\title{
O impacto do 11 de Setembro no desenvolvimento da Política de Segurança e Defesa da União Europeia $(2001-2010)^{1}$
}

The impact of the September $11^{\text {th }}$ on the development of the European Union Security and Defense Policy (2001-2010)

Elias David Morales Martinez ${ }^{2}$

Jacqueline Oliveira Mendes ${ }^{3}$

\section{Resumo}

Este artigo discute o impacto do 11 de Setembro na Politica de Segurança e Defesa da União Europeia no periodo 2001-2010. Analisa-se como tais eventos alteraram a integração do bloco em matéria de segurança causando cisão e divergência entre os países europeus, que preferiram atuar de forma isolada.

Palavras-chave: Terrorismo. Politica de Segurança e Defesa da Uniāo Europeia. Integração Regional.

\begin{abstract}
This paper discusses the impact of September $11^{\text {th }}$ on the Security and Defense Policy of the European Union during the period 2001-2010. It is analyzed how such events changed the bloc integration about security matters and how caused a divergence between the European countries which preferred to act isolated.

Keywords: Terrorism, Security and Defense Policy of the European Union, Integration.
\end{abstract}

1 Esta pesquisa contou com o apoio das agencias brasileiras de fomento à pesquisa CNPq/CAPES.

2 Doutor em Integração da América Latina, Práticas Políticas e Relaçôes Internacionais, PROLAM/USP. Professor do Programa de Pós-Graduação em Relaçóes Internacionais, Universidade Federal do ABC, PRI/UFABC; da Pós-Graduação em Ciências Humanas e Sociais CHS/UFABC e Bacharelado em Relaçôes Internacionais BRI/UFABC. São Paulo/Brasil. ORCID: http://orcid.org/0000-0002-8240-8581 (iD)

3 Formada em Ciências e Humanidades, Universidade Federal do ABC; Bacharel em Relaçôes Internacionais, UFABC. São Bernardo do Campo/Brasil. ORCID: https://orcid.org/0000-0003-4314-412X (iD) 


\section{Introdução}

Logo após o fim da Segunda Guerra Mundial, a Europa Ocidental iniciou um processo de integração econômica sem precedentes na história. Apesar dos momentos de questionamento, a opção do bloco sempre foi avançar nessa área. Ao longo do século XX, o continente aprofundou o processo de integração com a criação de novas instituiçôes e mais países se juntaram gradualmente ao bloco. Em 1993, através do Tratado de Maastricht, a União Europeia (UE) finalmente foi instituída.

Com os atentados de setembro de 2001 nos Estados Unidos da América (EUA) a ameaça terrorista alcançou novas proporçóes, pois havia atingido a maior potência do mundo. Seria necessário, entâo, implementar políticas que fossem contra tais ameaças. Além disso, os eventos provocaram uma resposta unilateral dos EUA que invadindo o Iraque em 2003, alegando que o então presidente, Saddam Hussein (1979-2003), possuía armas de destruição em massa nesse país. A ação não foi aprovada pelo Conselho de Segurança da Organização das Naçóes Unidas (ONU) e promoveu uma divisão entre os países europeus - alguns apoiaram a invasão enquanto outros foram contra.

Para nortear o desenvolvimento desta pesquisa, utilizamos a análise teórica da integração regional. Pretende-se identificar de que forma se deu o combate ao terrorismo dentro da Europa após os atentados de 2001 e a subsequente invasão do Iraque. Portanto, nosso objetivo principal é analisar como a UE reagiu aos atentados de setembro de 2001 e à resposta norte-americana - identificando de que forma os atentados influenciaram as estruturas de segurança na integração regional do bloco. A nossa hipótese é que os ataques não foram suficientes para promover uma maior integração supranacional na área de segurança e defesa entre os Estados da UE e que a reação dos EUA dividiu os membros do bloco, fazendo com que cada país agisse de forma isolada contra o terrorismo.

\section{Análise Teórica da Relação entre Segurança e Integração Regional}

A teoria realista das Relaçóes Internacionais vê o Estado como o principal ator nas relações internacionais. Ele é um agente unitário, autônomo e racional que busca seus interesses através de um cálculo de custos e benefícios. O interesse nacional último é sobreviver dentro do sistema internacional, que é permanentemente anárquico. Portanto, a segurança se torna um assunto mais urgente que todos os outros temas e a força militar é o principal instrumento para que um país alcance seus objetivos. Os Estados também têm como objetivo maximizar seu poder. $\mathrm{O}$ medo é a principal motivação da ação estatal, de forma que a segurança, o prestígio e o poder do país devem ser aumentados (KIRSHNER, 2009).

O realismo ganhou força após as Guerras Mundiais e durante a Guerra Fria, mas encontrou problemas na análise da regionalização. Kirshner (2009) admite que a análise realista do processo de integração regional é rasa pois não leva em conta o que a motivou: a globalização. Tal processo tem alterado o modo como os países se relacionam, pois eles têm procurado outros meios para aumentar sua proteção e autonomia frente à globalizaçáo. Portanto, o realismo ainda pode ser utilizado para analisar o processo de integração regional, mas deve incluir a globalização na análise, pois o processo traz à tona novos atores que afetam as ações estatais.

Assim, a globalização altera a segurança nacional de três maneiras: diminui a autonomia e a capacidade do Estado frente a atores não estatais; altera o equilíbrio de poder entre os Estados, através de uma redistribuiçẫo de capacidades e vulnerabilidades - os países são afetados de diferentes formas pela globalização e isso pode alterar a balança de poder; e, por último, o fenômeno influencia 
a natureza e as formas de conflito, especialmente através dos avanços tecnológicos. Assim, a integração regional seria o modo mais seguro de o Estado contornar as condições impostas pela globalização e aumentar sua margem de manobra frente a atores não estatais (KIRSHNER, 2009).

Schirm (1996) caracteriza a globalização como um conjunto de atores e sistemas que não são formados de acordo com um interesse estatal e não são moldados pelo território nacional, pois agem globalmente. No início dos processos de integração regional os atores transnacionais assumiram grande importância, especialmente na área econômica. A fragilidade territorial era crescente e as fronteiras nacionais haviam se tornado mais permeáveis. Além disso, os Estados tinham mais dificuldades de controlar o mercado interno frente às pressóes do mercado global. Esse contexto de globalização, que teve início nos anos 1970, foi a causa dos processos de integração regional. A partir desse momento, o Estado foi constrangido e sua capacidade de atingir seus objetivos foi diminuída. Os atores transnacionais são difíceis de regular e pressionam os Estados a se adaptarem às suas expectativas e padrōes. Dessa forma, os países estão cada vez mais incapazes de se isolarem de pressóes externas.

Uma governança conjunta entre os países de uma mesma regiáo torna-se uma opção para enfrentar os constrangimentos impostos pelos atores transnacionais. Dessa forma, a globalização se tornou um estímulo à governança regional. A integração é uma política melhor de regulação frente às novas pressōes e aos novos atores no sistema internacional, pois pode alcançar atores transnacionais. Como consequência, a governança regional pode aumentar a capacidade dos Estados de atingirem prosperidade e segurança dentro de seu território. Além disso, a competiçẫo entre Estados vizinhos seria reduzida, dada a área de governança comum estabelecida. Isso não significa que o Estado será superado pelas instituiçôes supranacionais. Ao contrário, a governança regional complementa a nacional pois possibilita ações conjuntas através de instrumentos comuns. Dessa forma, os objetivos estatais podem ser alcançados mais facilmente do que se as açôes fossem realizadas individualmente (SCHIRM, 1996).

A partir do ponto de vista de Kirshner (2009) e Schirm (1996), vemos que o realismo não enxerga as instituiçóes regionais como substitutas dos Estados. A integração regional seria a melhor resposta estatal frente aos novos desafios impostos pela tecnologia e pelo avanço de atores não estatais. A capacidade de controle dos países foi afetada por atores não estatais que não se prendem a territórios nacionais. Assim, uma forma do Estado retomar o controle seria por meio da governança conjunta, que é realizada através das instituiçôes regionais.

$\mathrm{O}$ terrorismo é um fenômeno que não se limita a fronteiras nacionais e é um dos desafios que os Estados enfrentam com a globalização. Partindo dessa concepção realista de integração, podemos admitir que os Estados não terão sucesso se combaterem o terrorismo isoladamente. Desde os atentados de setembro de 2001 os países têm investido em ações unilaterais contra o terrorismo. No entanto, isso não coibiu novos ataques, antes eles têm se proliferado cada vez mais, especialmente na Europa. Por tanto, é preciso, repensar se os instrumentos regionais não seriam a melhor forma dos países combaterem o terrorismo emergente no continente.

\section{Breve Histórico da União Europeia com foco na Segurança até 2001}

A integração regional na Europa começou após a Segunda Guerra Mundial. A primeira iniciativa na área de segurança se deu com o Tratado de Bruxelas (1948), que criou a União Europeia Ocidental (UEO). A organização tinha como objetivo estabelecer um instrumento de segurança coletiva 
para os países participantes, mas não foi capaz de articular com determinada eficiência os diferentes interesses. Portanto, a Organização do Tratado do Atlântico Norte $(\mathrm{OTAN})^{4}$ foi o principal fórum de defesa e segurança durante todo esse período na regiāo. A organizaçấo foi estabelecida pelos EUA para firmar sua liderança militar na Europa ocidental e também como instrumento de defesa contra um possível ataque e avanço do bloco soviético em espaço estratégico europeu (PECEQUILO, 2014).

Enquanto a integração política encontrava resistência, a possibilidade de cooperação em setores econômicos estratégicos gerou um plano concreto (Ibidem). França e Alemanha iniciaram um processo de integração através da Comunidade Europeia do Carvão e do Aço (CECA). Com base no sucesso da organização, em 1958 o Tratado de Roma estabeleceu a Comunidade Econômica Europeia (CEE) e a Comunidade Europeia de Energia Atômica (EURATOM). Em 1965 o Tratado de Bruxelas estabeleceu a fusão entre as instituiçóes através da Comunidade Europeia (CE).

A França de De Gaulle (1959-1969), no entanto, resistia ao poder supranacional da CE - o Tratado de Roma permitia que algumas questóes fossem solucionadas através de maioria qualificada, facilitando a tomada de decisões na organização. A mudança não agradou De Gaulle. O general também foi contra a adesão do Reino Unido à $\mathrm{CE}$ em 1963 e mais uma vez em 1967. A França temia a influência dos EUA no bloco, visto a relação privilegiada entre Washington e Londres (D’ARCY, 2002).

Dessa forma, a integração em política externa avançou somente a partir dos anos 1970. Em 1973 ocorreu a Conferência sobre Segurança e Cooperaçáo na Europa $(\mathrm{CSCE})^{5}$. O evento resultou nos Acor-

\footnotetext{
4 A organização está em vigor até hoje.

5 Com o fim da Guerra Fria, a CSCE adquiriu instituiçôes permanentes e se tornou a Organização para Segurança e Cooperaçáo na Europa (OSCE).
}

dos de Helsinque, que permitiram um diálogo direto entre os países ocidentais e orientais da Europa, sem grandes interferências das duas superpotências (BINDI, 2010). Essa iniciativa mostra que, apesar da liderança americana e soviética, os países europeus buscavam alternativas para estabelecer relações.

O Tratado de Maastricht entrou em vigor em 1993 e consolidou a integração do continente através da UE (art. A do TRATADO DA UNIÃO EUROPEIA, 1992). Os objetivos principais do tratado incluíam consolidar a união econômica e estabelecer uma política externa e de segurança comum (UNIÃO EUROPEIA, 2010a). Além disso, foram estabelecidas três dimensôes de integração, também conhecidas como os três pilares: dimensão comunitária, que incluía a área econômica; dimensão securitária, na qual ficou estabelecida a Política Externa e de Segurança Comum (PESC); e dimensão judiciária (PECEQUILO, 2014).

$\mathrm{Na}$ área da PESC, ficou estabelecido que a cooperação em política externa poderia ocorrer através de ações conjuntas. O tratado apontou o Conselho Europeu como responsável pela área, com o auxílio dos outros órgãos. O principal foco deveria ser em questóes mais simples, como missóes humanitárias. Assim, o objetivo não era sobrepor-se às políticas externas de cada país, mas construir uma estratégia comum a todos os membros do bloco (PECEQUILO, 2014).

Em 1999 o Tratado de Amsterdã aprofundou e ao mesmo tempo reformou os pilares estabelecidos em Maastricht. Na PESC foi criado o cargo de Alto Representante da União para os Negócios Estrangeiros e a Política de Segurança. Apesar dos avanços, na Guerra da Iugoslávia (1991-2001) e na do Kosovo (1998-1999) a Europa ainda se encontrava muito dependente da ação dos EUA através da OTAN. A organização foi a única capaz de intervir no conflito, demonstrando a fragilidade da política externa do bloco (BINDI, 2010). 
Portanto, durante o período analisado, a integração europeia em segurança e defesa foi tímida se compararmos com a área econômica. Mesmo com a consolidação em Maastricht, a PESC se concentrou em questôes mais simples que não geravam divergências significativas entre os membros do bloco.

\section{O Impacto dos Atentados de 2001 na Política de Segurança e defesa da UE no período de 2001 a 2010}

O uso do método terrorista para alcançar objetivos políticos já era conhecido pela Europa antes dos atentados de 2001 em Nova Iorque. O Exército Republicano Irlandês (IRA, para a sigla em inglês - Irish Republican Army) e o grupo basco ETA (Euskadi Ta Askatasuna, Pátria Basca e Liberdade em basco) utilizaram de métodos terroristas no Reino Unido e na Espanha respectivamente. Ainda na Itália o grupo comunista de guerrilha Brigada Vermelha também utilizou de métodos terroristas nos anos 1970 e 1980 . No entanto, a partir de 2001 os atentados terroristas ganharam novo formato pois não defendiam um objetivo político claro e não se baseavam num único território. Portanto, muitos membros do bloco tinham experiência em combater o terrorismo nacional, mas tiveram que fazer ajustes ao lidar com o terrorismo internacional (CAMERON, 2012).

Os ataques em setembro de 2001 podem ser considerados um ponto de ruptura no sistema internacional, pois os EUA se sentiam invulneráveis desde o fim da Guerra Fria - o último ataque em solo americano havia ocorrido durante a Segunda Guerra Mundial em Pearl Harbor (1941). Como país mais poderoso do mundo, os EUA conseguiram projetar seu poder militar em quase todas as partes do globo. $\mathrm{O}$ governo norte-americano entendeu os ataques terroristas como um ato de guerra e como um de- safio à sua posição de hegemon. Dadas tais circunstâncias, uma ação rápida e unilateral seria preferível (BARBOSA, 2002). O governo norte-americano argumentou, entâo, que se tratava de uma luta entre o "bem" e o "mal", o que justificaria uma resposta unilateral e eliminaria a necessidade de legitimar a intervenção nos organismos internacionais.

Como consequência, a chamada "Guerra ao Terror" teve como principal alvo o regime do Talibá no Afeganistão, que estaria apoiando a Al-Qaeda. Em outubro de 2001 os militares americanos iniciaram uma ofensiva para derrubar o regime afegão. Ainda em 2001, o Conselho Europeu elaborou um Plano de Ação contra a ameaça e o terrorismo se tornou prioridade para o bloco. O Plano de Ação tinha como objetivo reforçar a cooperação policial e judicial entre os membros do bloco (WAHL, 2010). Dessa forma, os países europeus escolheram fortalecer os meios legais de cooperação.

Em 2003 os EUA invadiram o Iraque alegando que o então presidente do país, Saddam Hussein (1979-2003), possuía armas de destruição em massa. No mesmo ano, Hussein foi capturado e deposto. Ao contrário da ação no Afeganistão, essa intervenção recebeu várias críticas. O Conselho de Segurança da ONU não aprovou a invasão. Alemanha e França foram contra a intervenção, enquanto o Reino Unido e outros países da UE apoiaram os EUA. O bloco europeu, entáo, se mostrou dividido frente à reação americana (MORAES; SOUZA, 2015).

Ainda em 2003, o Conselho Europeu lançou um documento sobre a segurança do continente. Nele foram identificados os principais perigos contra o bloco para que fosse construída uma abordagem multilateral (UNIÂO EUROPEIA, 2003). Em março de 2004, a cidade de Madri sofreu uma sequência de atentados que deixaram 192 mortos. Após os eventos, uma série de objetivos estratégicos de combate ao terrorismo foi adicionada ao Plano de 
Ação. Além disso, foi criado o cargo de Coordenador da Luta Antiterrorista (NOIVO; SEABRA, 2010).

Em julho de 2005 foi a vez de Londres presenciar uma serie de atentados terroristas em diferentes pontos da cidade deixando o trágico resultado de 56 mortos. A ação foi reivindicada por um grupo extremista islâmico que supostamente tinha ligaçóes com o Al-Qaeda. Após os ataques, foi elaborada a Estratégia Antiterrorista, que focou principalmente no combate à radicalizaçáo e ao recrutamento de terroristas. Esse documento foi importante pois representou o consenso entre os Estados-membros (CAMERON, 2012). Além disso, o terrorismo foi considerado uma ameaça que não pode ser combatida de forma isolada (WAHL, 2010).

Em 2007, foi assinado o Tratado de Lisboa. Ele explicitou a existência de interesses externos comuns aos membros do bloco e teve como objetivo capacitar a UE como um ator coeso (TEIXEIRA, 2010). No entanto, a área de política externa e segurança permaneceram intergovernamentais. As diretrizes e a execução ainda ficaram a cargo das instituições que representavam os interesses dos membros, mostrando que a integração regional em áreas mais sensíveis ainda encontraria resistência por parte dos Estados (SOARES, 2011).

Em 2010 o bloco lançou um novo documento na área de segurança. $O$ terrorismo continuou sendo considerado como uma das principais ameaças em plena emergência, e principalmente, a crescente preocupação de existirem relações perigosas dele com as novas tecnologias. A estratégia do bloco contra a ameaça seria focar na prevenção e cortar suas fontes de financiamento (UNIÁO EUROPEIA, 2010b). No entanto é perceptível que para cada país membro da União existem prioridades de segurança e defesa para atender assim como diversos graus de percepção que oscilam com relação ao tratamento dado ao terrorismo, daí a necessidade de projetos e estratégias conjuntas que represen- tem não só a identidade, mas também os interesses mais gerais da região.

Vemos que a UE possui uma estratégia muito mais reativa no combate ao terrorismo. Os documentos e objetivos foram elaborados após ataques terroristas em solo europeu. A UE implantou uma série de mecanismos para combater a ameaça - organizaçôes foram criadas, medidas judiciais foram implantadas e uma série de mecanismos de combate ao terrorismo foi instituída. No entanto, percebemos na nossa análise, que existe uma distância entre as decisôes do bloco e sua efetiva implementação. $\mathrm{O}$ compartilhamento de inteligência, por exemplo, é essencial para combater o terrorismo. Mas é difícil convencer países mais fortes nessa área, como França e Alemanha, a compartilhar informaçóes com países mais frágeis e que ingressaram recentemente no bloco, como Romênia e Croácia.

Além disso, temos o caso da intervenção dos EUA no Iraque. O bloco ficou dividido entre os países que apoiaram a ação e os que foram contra: os EUA receberam críticas de vários países, incluindo Alemanha e França. O Reino Unido e outros países europeus apoiaram a invasão, como Itália, Polônia, Holanda, Dinamarca, Portugal e Espanha. Dessa forma, a invasão do Iraque representa a falha da PESC, pois a divisão dentro da UE bloqueou decisões que poderiam ser tomadas na área. Sem atingir o consenso, foi impossível estabelecer uma política cooperativa de combate ao terrorismo dentro do bloco (PEREIRA, 2005).

\section{Conclusão}

Após ser o centro de duas guerras mundiais, a Europa iniciou um processo de integração para impedir o avanço de novos conflitos e também para fazer frente ao bloco soviético. A integração econômica, no entanto, se mostrou como a opçáo preferida e foi aprofundada durante o século XX. O Tratado de 
Maastricht consolidou o bloco como um novo tipo de ator no cenário internacional e preparou o terreno para a integração monetária. A UE foi organizada em três pilares e a PESC foi instituída com o objetivo de estabelecer uma estratégia de política externa que seria comum a todos os membros do bloco.

Com os atentados em setembro de 2001, ficou claro que os países aliados dos EUA também poderiam ser alvos de ataques. A UE precisava implantar medidas de combate ao terrorismo, visto sua forte relação com os EUA desde o fim da Segunda Guerra Mundial. O bloco ficou dividido entre os países que apoiaram a intervenção americana no Iraque e os que foram contra tal ação. Mesmo assim a UE implantou uma série de medidas para combater a ameaça.

Existe uma distância entre as decisóes do bloco e sua efetivação. O que está descrito formalmente nos documentos sobre a PESC não repercutiu nas práticas da UE, pois se tratou de discursos relacionados ao contexto político do momento. Vemos que após períodos de crise, declaraçôes conjuntas e ações coletivas são vistas como importantes e são implementadas. No entanto, essa percepção pode ser passageira e dificilmente pode gerar políticas de cooperação duradouras, principalmente quando há mudanças de governos, os quais não necessariamente dão continuidade com as políticas de Estado que estavam sendo implementadas previamente.

Apesar da efetividade da UE não poder ser analisada somente pelos documentos e declaraçóes, o foco desta pesquisa foi centrado justamente nesses itens pelo fato de observar que de alguma forma, eles têm certa capacidade de orientar as açóes do bloco, mesmo que os Estados ainda sejam os grandes responsáveis pela agenda securitária.

Além disso, ao analisar a integração da Europa vemos que açóes unilaterais baseadas no realismo clássico têm se mostrado ineficazes contra o avanço do terrorismo. Numa guerra entre dois países o inimigo é identificável e as batalhas ocorrem em determinados lugares. Na "guerra ao terror", no entanto, o inimigo não tem rosto definido, pois qualquer pessoa pode ser percebida como um terrorista em potencial. A tendência é que os ataques acontecem em qualquer lugar e afetam principalmente civis. Além disso, os grupos terroristas se organizam em redes, de forma que a tomada de decisões é mais rápida e flexível. Ações militares tradicionais contra grupos terroristas têm se mostrado inadequadas. Ao contrário, o uso da força contra um inimigo "invisível” atingiu muitos civis no Oriente Médio e têm deslegitimado as intervenções.

O terrorismo é um fenômeno que não se limita às fronteiras nacionais e é um dos desafios que os Estados enfrentam com a globalização. Partindo da concepção realista de integração de Kirshner (2009) e Schirm (1996), podemos admitir que os Estados não terão sucesso se combaterem o terrorismo isoladamente. Desde os atentados de setembro de 2001 os países têm investido em açóes unilaterais contra o terrorismo. No entanto, isso não coibiu novos ataques, antes eles têm se proliferado cada vez mais, especialmente na Europa. É preciso, então, repensar se os instrumentos regionais não seriam a melhor forma dos países combaterem o terrorismo no continente.

Vemos, então, que os ataques terroristas de 2001 não foram suficientes para promover uma maior integração supranacional na área de segurança e defesa entre os Estados da UE. Apesar de vários documentos e declaraçóes de combate ao terrorismo terem sido lançadas pelo bloco, a invasão do Iraque pelos EUA em 2003 dividiu os Estados-membros, fazendo com que cada país agisse de forma isolada contra o terrorismo. A divisão intereuropeia teve consequências na questão de política externa do bloco, impedindo o aprofundamento da integração do ponto de vista supranacional. Mas o fato dos Estados resistirem em transferir/compartilhar responsabilidades com uma instituição supranacional ainda é o maior impedimento para que as medidas da UE contra o terrorismo tenham mais efetividade. 


\section{REFERÊNCIAS}

BARBOSA, R. A. Os Estados Unidos pós 11 de Setembro de 2001: implicaçóes para a ordem mundial e para o Brasil. Revista Brasileira de Política Internacional, Brasília, v. 45, n. 1, p. 72-91, jun. 2002. Disponível em: <http://www.scielo.br/scielo.php?script=sci_arttext\&pid=S0034-73292002000100003> Acesso em: 21 nov. 2018.

BINDI, F. European Union Foreign Policy: A Historical Overview In: BINDI, F. The Foreign Policy of the European Union: assessing Europe's role in the world. Washington: The Brooking Institution, cap. 1, p. 13-40, 2010. Disponível em: <http://hist. asu.ru/aes/FPEU_0815701403.pdf>. Acesso em: 21 nov. 2018.

CAMERON, F. An Introduction to European Foreign Policy. 2. Ed. Nova York: Routledge, 2012. 293 p.

D'ARCY, F. Uniâo Europeia: instituiçôes, políticas e desafios. Rio de Janeiro: Konrad Adenauer Stiftung, 2002, 248 p.

KIRSHNER, J. Realistic Political Economy: traditional themes and contemporary challenges. In. BLYTH, M. Routledge Handbook of International Political Economy (IPE). Londres: Routledge, p. 36-47, 2009.

MORAES, R. F.; SOUZA, A. M. Coalizóes Globais Lideradas pelos Estados Unidos na Guerra ao Terror (20012011): para além do unilateralismo. Contexto Internacional, Rio de Janeiro, v. 37, n. 2, p. 763-790, ago. 2015. Disponível em: <http://www.scielo.br/scielo.php?script=sci_arttext\&pi$\mathrm{d}=$ S0102-85292015000200763\&lng=en\&nrm=iso>. Acesso em: 21 nov. 2018.

NOIVO, D.; SEABRA, P. Combate ao Terrorismo na União Europeia: construção de uma abordagem comum. Revista Segurança e Defesa, Loures, v. 1, p. 36-47, 2010.

PECEQUILO, C. S. A Uniáo Europeia: os desafios, as crises e o futuro da integração. Rio de Janeiro: Elsevier, 2014. 184 p.

PEREIRA, D. C. Uniáo Europeia: a política externa e de segurança comum em mundo unipolar. 2005. 150 f. Dissertação (Mestrado em Relaçôes Internacionais) - Instituto de Filosofia e Ciências Humanas, Universidade Estadual de Campinas, Campinas, 2005.
SCHIRM, S. A. Transnational Globalization and Regional Governance: on the reasons for regional cooperation in Europe and the Americas. Cambridge: Center for European Studies, v. 6, n.2, 1996.

SOARES, A. G. A União Europeia como potência global? As alteraçóes do Tratado de Lisboa na política externa e de defesa. Revista Brasileira de Política Internacional, Brasília, vol. 54, n. 1, p. 87-104, 2011. Disponível em: <http://dx.doi.org/10.1590/ S0034-73292011000100006>. Acesso em: 21 nov. 2018.

TEIXEIRA, N. S. A Defesa Europeia depois do Tratado de Lisboa. Relaçóes Internacionais, Lisboa, n. 25, p. 21-29, mar. 2010. Disponível em: <http://www.scielo. gpeari.mctes.pt/scielo.php?script=sci_arttext $\&$ pid $=$ S164591992010000100004\&lang=pt>. Acesso em: 21 nov. 2018.

TRATADO DA UNIÃO EUROPEIA. Maastricht. Jornal Oficial das Comunidades Europeias, 29 jul. 1992. Disponível em: <http://eur-lex.europa.eu/legal-content/PT/TXT/ $\mathrm{PDF} /$ ?uri=CELEX:11992M/TXT\&from=EN>. Acesso em: 21 nov. 2018

UNIĀO EUROPEIA. Conselho Europeu. A Secure Europe in a Better World: European security strategy. Bruxelas, 2003. Disponível em: <https://europa.eu/globalstrategy/en/european-security-strategy-secure-europe-better-world>. Acesso em: 05 jun. 2018.

UNIÃO EUROPEIA. Estratégia de Segurança Interna da Uniáo Europeia: rumo a um modelo europeu de segurança. Bruxelas: Serviço das Publicaçôes da União Europeia, 2010b. 31 p. Disponível em: <http://www.consilium.europa.eu/media/30754/qc3010313ptc.pdf>. Acesso em: 05 jun. 2018.

UNIĀO EUROPEIA. Tratado de Maastricht sobre a União Europeia. Última atualização em 15 out. 2010a. Disponível em <http://eur-lex.europa.eu/legal- content/PT/TXT/?uri=LEGISSUM:xy0026>. Acesso em: 21 nov. 2018.

WAHL, T. The European Union as an Actor in the Fight against Terrorism. In: MALJEVIĆ, A.; WADE, M. A War on Terror? Nova York: Springer, p. 107-170, 2010. 